\title{
Early recognition of autonomic dysfunction in microalbuminuria: significance for cardiovascular mortality in diabetes mellitus?
}

\author{
H. Mølgaard ${ }^{1}$, P.D. Christensen ${ }^{1}$, K.Hermansen ${ }^{2}$, K. E.Sørensen ${ }^{1}$, C. K. Christensen ${ }^{3}$, C. E.Mogensen ${ }^{3}$ \\ ${ }^{1}$ Department of Cardiology, Skejby University Hospital, Århus, Denmark \\ ${ }^{2}$ Institute of Electronic Systems, Aalborg University Center, Aalborg, Denmark \\ ${ }^{3}$ Department of Medicine M (Diabetes and Endocrinology), Århus University Hospital, Århus, Denmark
}

Summary The appearance of microalbuminuria in diabetic patients predicts development of macroalbuminuria and coronary heart disease. Autonomic dysfunction in ischaemic heart disease is related to an increased incidence of arrhythmic deaths. To assess sympathovagal balance in relation to microalbuminuria we performed 24-h spectral analysis of RR interval oscillations in 37 insulin-dependent diabetic patients. $\mathrm{Pa}-$ tients were divided according to urinary albumin excretion as normo- $(<20 \mu \mathrm{g} / \mathrm{min})(n=12)$, micro- $(>20$ and $<200 \mu \mathrm{g} / \mathrm{min})(n=14)$ and macro-albuminuria $(>200 \mu \mathrm{g} / \mathrm{min})(n=11)$. None had symptoms or signs of ischaemic heart disease at clinical examination or during stress testing. Fourteen matched healthy subjects served as controls. Overall RR interval variability was calculated as the 24-h standard deviation. The square root of power of the low-frequency $(0.04$ $0.15 \mathrm{~Hz})$ and high-frequency $(0.15-0.40 \mathrm{~Hz})$ component were considered indices of the sympathovagal interaction and vagal function, respectively. Patients with micro and macroalbuminuria had, compared to control subjects, significantly reduced $24-\mathrm{h}$ standard deviation, a much smaller day/night difference in mean RR level and a significantly reduced amplitude of the low frequency and high frequency oscillations, which were even more reduced in macroalbuminuria. The differences in vagal function were also present after correction for mean RR level, and differences in physical training level and smoking. Insulin-dependent diabetic patients who develop microalbuminuria have significantly impaired vagal function and abnormal sympathovagal interaction, which is further deranged in macroalbuminuria. This early autonomic dysfunction may later contribute to a increased risk for sudden cardiac death. [Diabetologia (1994) 37: 788-796]

Key words Autonomic function, diabetes mellitus, 24-h heart rate variability, microalbuminuria, sudden cardiac death, vagal function, autonomic neuropathy.
Diabetic patients have a high cardiovascular mortality. The presence of macroalbuminuria (proteinuria) in IDDM patients is associated with a severely increased relative mortality from cardiovascular disease [1]. The

Received: 3 January 1994

and in revised form: 18 March 1994

Corresponding author: Dr. H. Mølgaard, Department of Cardiology, Skejby University Hospital, DK-8200 Ärhus N, Denmark

Abbreviations: CCV HF, Coefficient of component variance of high frequency power (HF power/mean RR); HF, high frequency; LF, low frequency; RR interval, distance between two ORS complexes (heart beats); SD, standard deviation; IDDM, insulin-dependent diabetes mellitus. incidence of coronary heart disease is very high, even during the first years of macroalbuminuria [2]. The appearance of slightly elevated urinary albumin excretion (microalbuminuria), is an early and good predictor for subsequent development of macroalbuminuria $[3,4]$.

Impaired cardiac autonomic function both in experimental and clinical studies predicts sudden cardiac death in coronary heart disease [5-8]. Severe autonomic dysfunction in diabetic patients, as evaluated by bedside tests, is associated with a poor prognosis, and case reports have related this to sudden cardio-respiratory death [9-14]. Quantification of RR interval fluctuations can be used to estimate autonomic activity. Results based on 24-h ECG recordings indicate that 
these measurements are more sensitive than ordinary bed-side tests to detect early autonomic neuropathy in diabetic patients [15-17]. Reduced overall 24-h RR interval variability (24-h SD) is associated with a high independent risk of sudden cardiac death in patients with established coronary heart disease $[6-8,18]$. The $24-h$ $\mathrm{SD}$ is a broad band measure of autonomic function reflecting both sympathetic and vagal activity. The power spectral analysis of RR interval fluctuations has provided a powerful new tool with which to assess the sympathovagal balance by analysis of $24-\mathrm{h}$ ECG recordings $[19,20]$. The aim of the present study was to assess the sympathovagal function in IDDM patients in relation to degree of albuminuria.

\section{Subjects and methods}

Patients: Fourteen healthy subjects and 37 IDDM patients were studied [16]. Upon clinical examination 12-lead ECG and stress test they were without symptoms and signs of heart disease. This was performed as a graded exercise test on an electronically braked ergometer bicycle, increased by $50 \mathrm{~W}$ every $3 \mathrm{~min}$, until exhaustion. Finally, patients were found to be without regional wall motion abnormalities during an echocardiographic examination. None were receiving cardiovascular medication during the study period, except for one patient taking $40 \mathrm{mg}$ furosemide daily for lower extremity oedema. Patients were divided into groups according to their urinary albumin excretion, based on three samples during an observation period of at least 6 months: $<20 \mu \mathrm{g} / \mathrm{min}$ (normoalbuminuria), $>20$ and $<200 \mu \mathrm{g} / \mathrm{min}$ (microalbuminuria), and $>200 \mu \mathrm{g} / \mathrm{min}$ (macroalbuminuria) [4, 21]. Urinary albumin excretion was determined together with glomerular filtration rate. The former by radioimmunoassay, the latter by the constant infusion technique with $\mathrm{I}^{-125}$ Iothalamate as marker, using 4-5 urine collection periods.

Patients were classified with regard to their participation in leisure-time physical activity as: 1) active in competitive sports (Active); 2) participants in leisure-time physical exercise (Intermediate); 3) not participants in such activities (Passive) [22, 23]. As there were few Active, the Active and Intermediate group were considered together.

Measurement of RR interval: The 24-h ECGs were recorded by a Tracker two-channel tape recorder during daily routine activities. Replay, QRS detection and measurement of the RR interval were performed by the Reynolds Pathfinder II system and our own software. We have previously evaluated the performance of this system with regard to QRS and RR interval detection [24]. The replay unit uses a phase-lock loop system and a speed surveyor, by which speed errors that might influence RR interval variability measurements can be omitted. Only cycles in which beats have normal morphologic characteristics are used for analysis. Additionally all intervals over $1.6 \mathrm{~s}$ and intervals deviating more than $-33 \%$ and $+66 \%$ from the preceding interval, were discharged. In the case of $24-\mathrm{h}$ test tapes recorded with exact $\mathrm{RR}$ intervals, measured mean $\mathrm{RR}$ corresponds exactly to true RR for test intervals $500-2000 \mathrm{~ms}$. The beat to beat variation, for $24-\mathrm{h}$ recordings of $1000 \mathrm{~ms}$ test intervals, calculated as the $\mathrm{SD}$ was $3 \mathrm{~ms}[24]$.

Each $24-\mathrm{h}$ recording was split into awake and sleep time. Sleep time was approximated according to diaries and a heart rate trend curve (heart rate per min). The typical pattern of the transition zone from being awake to sleep and vice versa were in- cluded in wake-time. Sleep time, therefore, consists of pure time spent sleeping.

Time domain analysis: We calculated the following time domain indices of RR interval variability: 1) the day-night difference in the mean $\mathrm{RR}$ and 2) overall variability as the $\mathrm{SD}$ of all intervals around the mean $R R$.

Frequency domain analysis: power spectral analysis of $\mathrm{RR}$ interval fluctuations evaluates the autonomic modulation of shortterm RR interval variability. The respiratory dependent HF oscillations of $0.15-0.40 \mathrm{~Hz}$ are mediated purely by vagal activity $[19,25]$. The power in the HF band is highest in the supine position $[19,20,26]$, is reduced in the upright position and completely abolished by atropine $[19,25]$. The square root of power of the $\mathrm{HF}$ component is linearly related to vagal tone as determined pharmacologically [25]. LF oscillations in the band of 0.04 $0.15 \mathrm{~Hz}$ are mediated by an interaction of sympathetic and vagal activity. In the supine position the power is highly dependent on vagal activity, whereas in the upright position both sympathetic and vagal activity contributes to these fluctuations $[19,25]$. The spectral power of the HF and LF component can be estimated in 5-min RR interval segments $[19,20,25,27]$. As we only wanted to identify and quantitate these two components, we used a model-based analysis. The $24-\mathrm{h}$ RR interval file was divided into consecutive 5-min segments, which were analysed separately. Power spectral analysis requires that time series data are equidistantly sampled. RR interval data inherently lack this equidistant character because each datum occurs whenever a QRS complex is detected. Therefore RR interval files were time equidistantly sampled at $4 \mathrm{~Hz}$, using an IPFM algorithm [27, 28]. Linear interpolation was used for periods with invalid data [27]. To qualify at least $70 \%$ of each segment should be normal intervals. After antialiasing, the files were downsampled to $1 \mathrm{~Hz}$, then high-pass filtered with a lower limit of $0.04 \mathrm{~Hz}$. After Hamming weighing the autocorrelation function was determined and used as input to the spectral analysis. We found that a model-based technique (Autoregressive method) performed better than the Fast Fourier technique [29], as it was more efficient in determining the centre frequencies, and thereby improved the signal to noise ratio. The ability to track and focus on the varying centre frequencies (Linear predicting coding technique) made it possible to eliminate more background noise. The magnitude of the two spectral components are given as the square root of

Fig.1. (A-C) 24-h power spectral analysis of RR interval oscillations in a healthy control subject. A: 24 -h RR interval variations, shown for consecutive 5-min segments. For practical reasons, only 300-s RR interval variations (one horizontal curve) for each $30 \mathrm{~min}$, is shown. Time of day is indicated on the right $y$-axis from 12.00 hours to 12.00 hours the following day. During sleep vagal dependent $\mathrm{HF}$ oscillations ( $\mathrm{HF} ; 0.15-0.40 \mathrm{~Hz}$ ) becomes prominent. The LF oscillation (LF; $0.04-0.15 \mathrm{~Hz}$ ) is dominant during day time. The RR interval series shown has been preprocessed for spectral analysis (time equidistant sampled, interpolated, removal of DC component etc). B: Mean RR per 5 min. Overall $R R$ variability $=24-h$ SD. $C$ : The result of the power spectral analysis of the RR interval segments shown in $\mathbf{A}$. The centre frequency is shown on the $X$-axis. Time of day on the right $Y$-axis, and the square root of power on the left $Y$-axis. CCV-HF $=$ coefficient of component variance for the HF component (square root power $\mathrm{HF} /$ mean $\mathrm{RR}$ )

Fig.2. (A-C) 24-h power spectral analysis of RR interval oscillations in a diabetic patient with microalbuminuria. Explanation as in Figure 1 

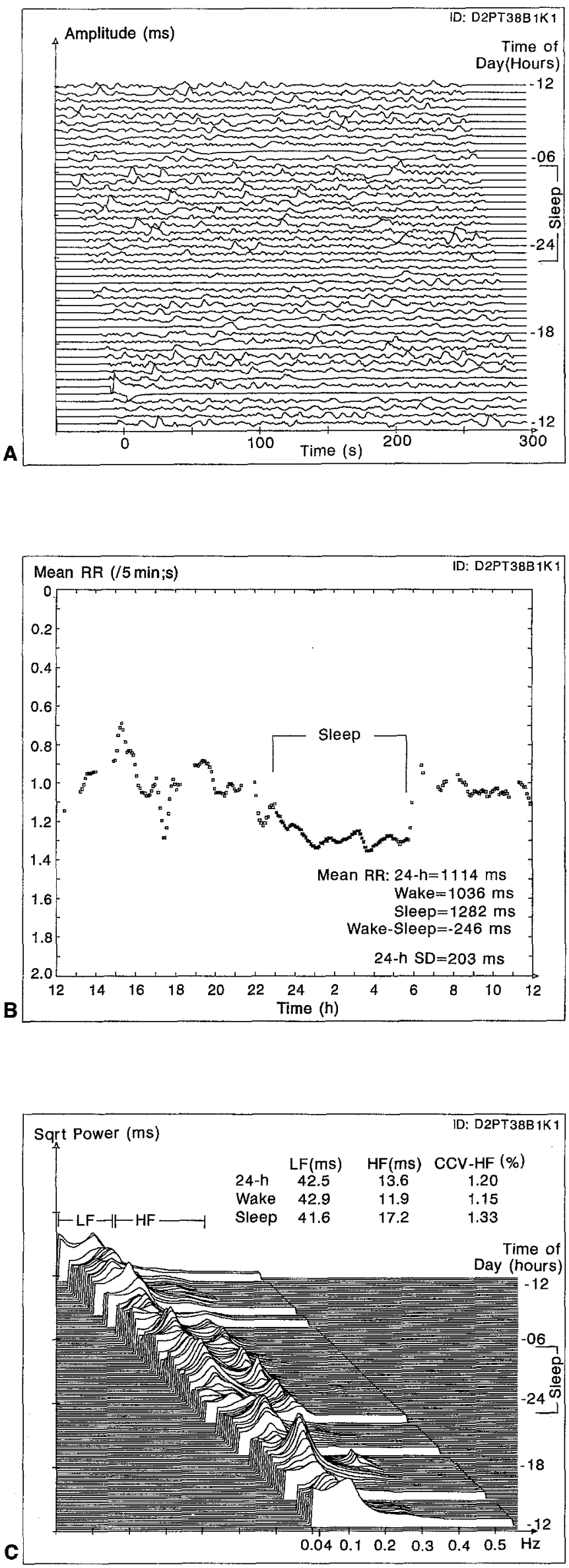
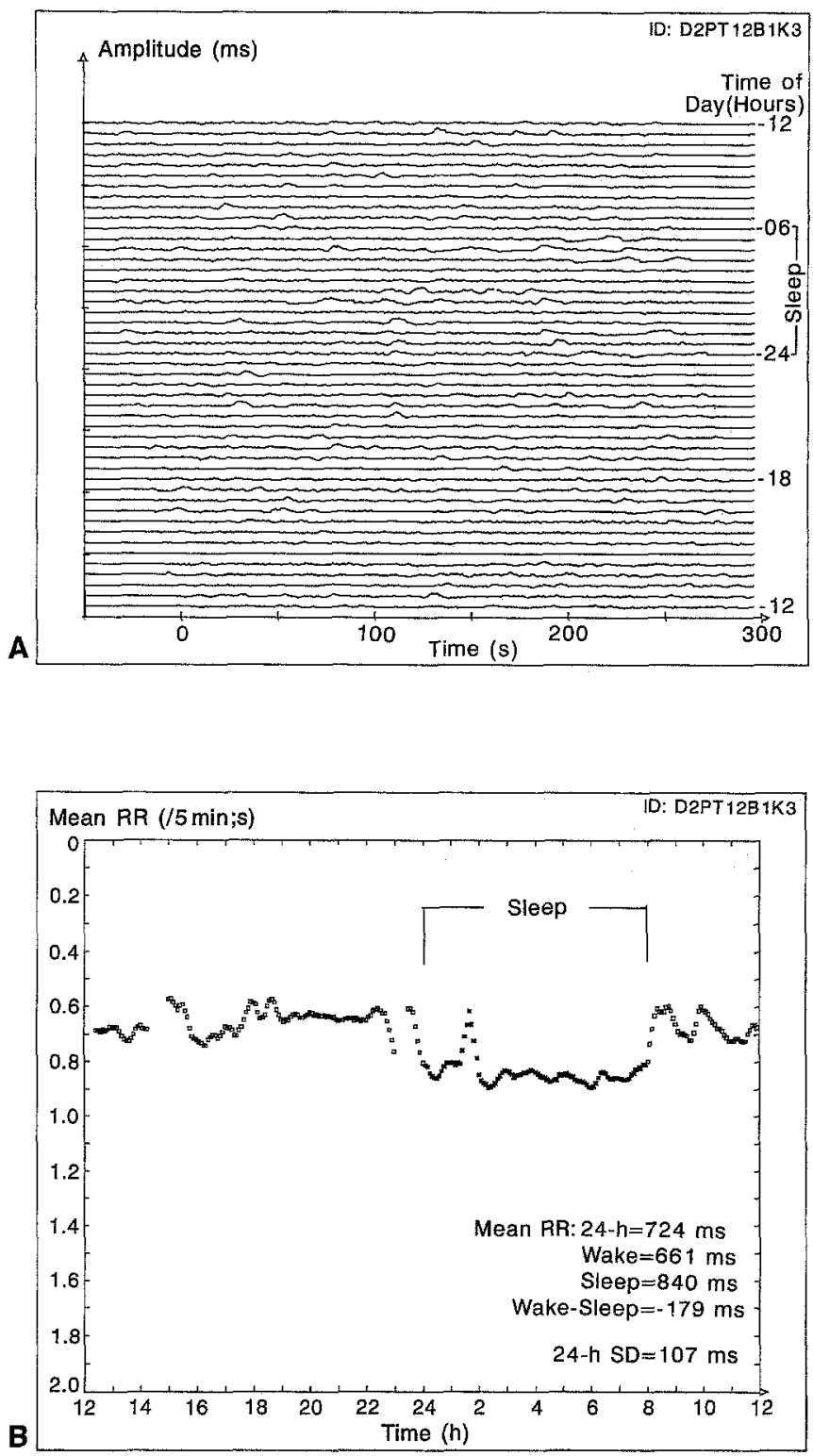

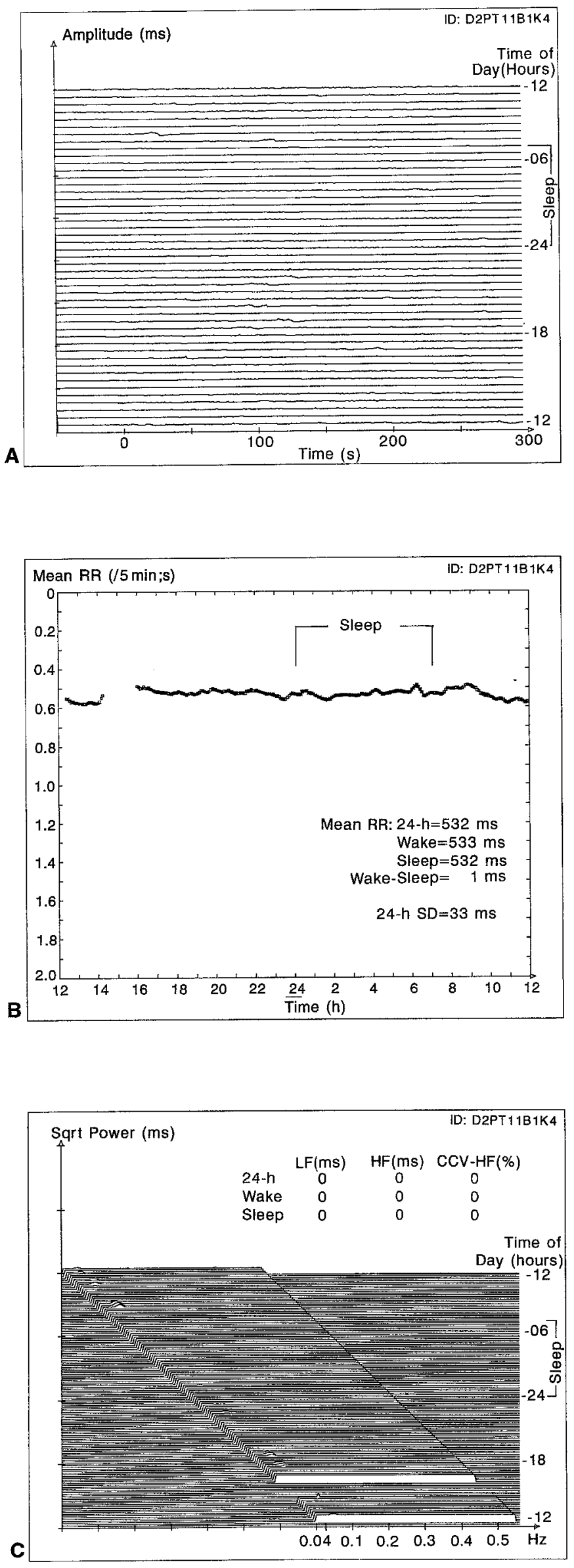

power (ms). For the HF component we also calculated the coefficient of component variance (square root of power/mean RR) (CCV HF). This parameter accounts for a possible impact of mean RR level on the amplitude of the HF component [25]. The amplitude of the smallest RR interval oscillation which can be detected validly corresponds to a square root of power of approximately $2.0 \mathrm{~ms}$. At or below this level any oscillation in the frequency band of $0.04-0.4 \mathrm{~Hz}$ cannot be distinguished from oscillations imposed by the recording and analysis system (testtapes). Figures for square root of power are given as a mean for all 24-h and for separate sleep and awake time. Figure 1-3A shows the preprocessed 24-h RR interval files from a healthy control subject and two diabetic patients with micro- and macroalbuminuria. In Figures 1-3 B heart rate trend curves are shown and in Figures 1-3C the 24-h spectral amplitude curves.

\section{Statistical analysis}

BMDP software was used. Differences between groups, for discrete variables, were evaluated by chi-square test. For continuous parameters, right skewed distributions were logarithmic transformed and values of 0.0 were entered as 0.04 . Group differences were tested by the $t$-test, or by Mann-Whitney tests. The correlation between degree of albuminuria, clinical characteristics and RR interval variability was tested by Kendalls Tau and linear trend. Group differences in LF, HF and CCV-HF were also tested after correcting for differences between groups in leisure-time physical activity and smoking (which have an impact on LF and HF values), using coefficients from healthy subjects [23].

\section{Results}

Clinical characteristics of the patients are shown in Table 1. Patients with macroalbuminuria had longer diabetes duration than patients with normoalbuminuria. Control of blood glucose $\left(\mathrm{HbA}_{1 \mathrm{c}}\right)$ was identical in the three groups. Although there was no significant difference between groups with regard to physical activity and smoking a significant trend towards less physical activity by increasing albuminuria, was present $(p=0.02)$. Table 2 shows mean 24 -h values for both short- and long-term RR interval variability, and in Table 3 figures for separate awake and sleep time. Table 4 shows the mean centre frequencies of the LF and HF component. All three groups of patients had significantly reduced mean RR level (faster heart rates) compared to healthy control subjects. However, the three groups did not differ significantly. Patients with micro and macroalbuminuria had attenuated day-night difference in mean RR level, whereas normoalbuminuric patients were not different from control subjects. The $24-\mathrm{h} \mathrm{SD}$ was significantly reduced in patients with micro and macroalbuminuria, whereas

Fig.3. (A-C) 24-h power spectral analysis of RR interval oscillations in a diabetic patient with macroalbuminuria. Explanation as in Figure 1 
Table 1. Clinical and renal characteristics of healthy non-diabetic control subjects and IDDM patients in relation to degree of microalbuminuria

\begin{tabular}{|c|c|c|c|c|c|c|c|c|c|}
\hline & $n$ & $\begin{array}{l}\text { Age } \\
\text { (years) }\end{array}$ & $\begin{array}{l}\text { Sex } \\
\text { (male/female) }\end{array}$ & $\begin{array}{l}\text { Non-smokers/ } \\
\text { smokers }(\%)\end{array}$ & $\begin{array}{l}\text { Leisure time } \\
\text { activity (\%) } \\
\text { Active/passive }\end{array}$ & $\begin{array}{l}\text { Duration } \\
\text { diabetes } \\
\text { (years) }\end{array}$ & $\begin{array}{l}\text { Albuminuria } \\
(\mu \mathrm{g} / \mathrm{min})\end{array}$ & $\begin{array}{l}\text { GFR } \\
(\mathrm{ml} / \mathrm{min})\end{array}$ & $\begin{array}{l}\text { Blood pressure } \\
\text { mean }(\mathrm{mmHg})\end{array}$ \\
\hline $\begin{array}{l}\text { Healthy control } \\
\text { subjects }\end{array}$ & 14 & $\begin{array}{l}32 \\
(23-41)\end{array}$ & $9 / 5$ & $64 / 36$ & $79 / 21$ & & $\begin{array}{l}3.6 \\
(2.3-6.2)\end{array}$ & $\begin{array}{c}119-134) \\
(100-134)\end{array}$ & $\begin{array}{c}87 \\
(80-97)\end{array}$ \\
\hline $\begin{array}{l}\text { Normo } \\
\text { albuminuria }\end{array}$ & 12 & $\begin{array}{l}28 \\
(21-36)\end{array}$ & $7 / 5$ & $50 / 50$ & $58 / 42$ & $\begin{array}{l}14 \\
(8-22)\end{array}$ & $\begin{array}{l}7.3 \\
(2.8-12.9)\end{array}$ & {$\left[\begin{array}{l}143-179) \\
(121-17\end{array}\right]$} & $\begin{array}{cc}90 & \\
(81-108) & a\end{array}$ \\
\hline $\begin{array}{l}\text { Micro } \\
\text { albuminuria }\end{array}$ & 14 & $\begin{array}{l}29 \\
(20-43)\end{array}$ & $7 / 7$ & $50 / 50$ & $57 / 43$ & $\left.18\right|^{\mathrm{a}}$ & $\begin{array}{l}56.7 \\
(24-134)\end{array}$ & a $150 \overline{(126-\overline{183})}$ & $\begin{array}{cc}95 & \\
83-114) & a\end{array}$ \\
\hline $\begin{array}{l}\text { Macro } \\
\text { albuminuria }\end{array}$ & 11 & $\begin{array}{l}31 \\
(23-37)\end{array}$ & $8 / 3$ & $36 / 54$ & $27 / 73$ & $\begin{array}{c}21 \\
(10-31)\end{array}$ & $\begin{array}{l}1547 \\
(219-4067)\end{array}$ & $\frac{100}{(46-136)}$ & $\begin{array}{l}109 \\
(87-123)\end{array}$ \\
\hline
\end{tabular}

Microalbuminuria was graded according to urinary albumin excretion as: normoalbuminuria $(<20 \mu \mathrm{g} / \mathrm{min})$, microalbuminuria ( $>20$ and $<200 \mu \mathrm{g} / \mathrm{min}$ ) and macroalbuminuria $(>200 \mu \mathrm{g} / \mathrm{min})$. Mean values shown, range in parantheses. ${ }^{\mathrm{a}}=p<0.05$

GFR, glomerular filtration rate

Table 2. 24-h RR interval variability in healthy control subjects and IDDM patients in relation to degree of microalbuminuria

\begin{tabular}{|c|c|c|c|c|c|c|}
\hline & $\begin{array}{l}\text { Mean RR } \\
\text { (ms) }\end{array}$ & $\begin{array}{l}\text { Mean RR day- } \\
\text { mean RR night } \\
\text { (ms) }\end{array}$ & $\begin{array}{l}24-h \\
\text { SD } \\
(\mathrm{ms})\end{array}$ & $\begin{array}{l}\text { Square root } \\
\text { power LF } \\
\text { (ms) }\end{array}$ & $\begin{array}{l}\text { Square root } \\
\text { power HF } \\
\text { (ms) }\end{array}$ & $\begin{array}{l}\text { CCV-HF } \\
(\%)\end{array}$ \\
\hline $\begin{array}{l}\text { Healthy control } \\
\text { subjects }\end{array}$ & $\left.\begin{array}{c}850 \\
(111)\end{array}\right\rceil$ & $\begin{array}{r}-219 \\
(61)\end{array}$ & $\begin{array}{l}158 \\
(32)\end{array}$ & $\left.\begin{array}{l}28.7 \\
(6.4)\end{array}\right]$ & $\left.\begin{array}{c}13.3 \\
(7.1)\end{array}\right]$ & $\begin{array}{c}1.44 \\
(0.66)\end{array}$ \\
\hline Normo albuminuria & $\begin{array}{c}766- \\
(97)\end{array}$ & $\begin{array}{r}-188 \\
(60)\end{array}$ & $\Gamma^{137}(38)$ & {$\left[\begin{array}{c}24.8 \\
(12.6)\end{array}\right.$} & {$\left[\begin{array}{c}12.2 \\
(10.7)\end{array}\right.$} & {$\left[\begin{array}{c}1.42 \\
(1.01)\end{array}\right]$} \\
\hline Micro albuminuria & $\begin{array}{l}753- \\
(137)\end{array}$ & $\begin{array}{c}-164 \\
(90)\end{array}$ & $\begin{array}{l}123- \\
(52)\end{array}$ & $\begin{array}{c}20.4- \\
(10.8)\end{array}$ & $\begin{array}{l}8.5- \\
(6.1)\end{array}$ & $\begin{array}{c}1.01- \\
(0.56)\end{array}$ \\
\hline Macro albuminuria & $\begin{array}{l}708- \\
(103)\end{array}$ & $\begin{array}{c}-145- \\
(76)\end{array}$ & $\begin{array}{c}-99] \\
(40)\end{array}$ & $\begin{array}{c}-13.8- \\
(11.3)\end{array}$ & {$\left[\begin{array}{l}5.3 \\
(2.9)\end{array}\right.$} & $\frac{L_{(0.38)}}{0.71-}$ \\
\hline
\end{tabular}

$24 \mathrm{~h} \mathrm{SD}$, Standard deviation of all RR intervals around mean RR; CCV-HF, square root of power HF/mean RR. ${ }^{\mathrm{a}} p<0.05$. Values are mean (SD)

Table 3. RR interval variability for wake and sleep time in healthy control subjects and IDDM patients in relation to degree of urinary albumin excretion

\begin{tabular}{|c|c|c|c|c|c|c|c|c|}
\hline & \multicolumn{2}{|c|}{ Mean RR (ms) } & \multicolumn{2}{|c|}{ Square root power LF (ms) } & \multicolumn{2}{|c|}{ Square root power HF (ms) } & \multicolumn{2}{|c|}{ CCV-HF (\%) } \\
\hline & Wake & Sleep & Wake & Sleep & Wake & Sleep & Wake & Sleep \\
\hline $\begin{array}{l}\text { Healthy control } \\
\text { subjects }\end{array}$ & $\begin{array}{c}785 \\
(103)]\end{array}$ & $\begin{array}{l}1004 \\
(132)\end{array} \mid$ & $\left.\begin{array}{l}27.7 \\
(5.6)\end{array}\right]$ & $\begin{array}{c}31.2 \\
(11.2)\end{array}$ & $\left.\begin{array}{c}9.8 \\
(4.1)\end{array}\right]$ & $\begin{array}{c}20.9 \\
(12.4)\end{array}$ & $\left.\begin{array}{c}1.18 \\
(0.42)\end{array}\right]$ & $\left.\begin{array}{c}2.01 \\
(1.14)\end{array}\right]$ \\
\hline Normo albuminuria & $\begin{array}{l}703-1 \\
(84)\end{array}$ & $\begin{array}{c}890^{\rfloor} \\
(120)\end{array}$ & {$\left[\begin{array}{c}24.2 \\
(10.7)\end{array}\right]$} & $\begin{array}{c}26.6 \\
(16.8)\end{array}$ & {$\left[\begin{array}{c}9.2 \\
(6.5)\end{array}\right]$} & $\begin{array}{c}17.3 \\
(16.2)\end{array}$ & $\mid\left[\begin{array}{c}1.20 \\
(0.71)\end{array} \mid\right.$ & {$\left[\begin{array}{c}1.81 \\
(1.44)\end{array}\right]$} \\
\hline Micro albuminuria & $\begin{array}{c}697- \\
(118)\end{array}$ & $\begin{array}{l}861- \\
(183)\end{array}$ & $\begin{array}{c}19.1 \\
(9.1)\end{array}$ & $\begin{array}{c}22.5 \\
(15.1)\end{array}$ & $\begin{array}{c}6.4 \\
(3.7)\end{array}$ & $\begin{array}{c}12.8 \\
(11.8)\end{array}$ & $\left|\begin{array}{c}L_{0.86} \\
(0.36)\end{array}\right|$ & $\begin{array}{c}1.33 \\
(1.06)\end{array}$ \\
\hline Macro albuminuria & $\begin{array}{l}659 \\
(85)\end{array}$ & $\begin{array}{l}804- \\
(138)\end{array}$ & $\begin{array}{c}{[13.1-} \\
(11.0)\end{array}$ & $\begin{array}{c}14.9 \\
(12.3)\end{array}$ & $\begin{array}{c}{[-4.3-]} \\
(2.3)\end{array}$ & $\begin{array}{l}7.2 \\
(4.4)\end{array}$ & $\frac{(0.34)}{-0.64]}$ & $\begin{array}{r}-0.84- \\
(0.50)\end{array}$ \\
\hline
\end{tabular}

$\mathrm{CCV}-\mathrm{HF}=\mathrm{square}$ root of power $\mathrm{HF} /$ mean RR. ${ }^{\mathrm{a}} p<0.05$.

Values are mean (SD) 
Table 4. Centre frequency of LF- and HF-component

\begin{tabular}{|c|c|c|c|c|c|c|}
\hline & \multicolumn{3}{|c|}{$\begin{array}{l}\text { Centre frequency LF } \\
(\mathrm{mHz})\end{array}$} & \multicolumn{3}{|c|}{$\begin{array}{l}\text { Centre frequency } \\
\mathrm{HF}(\mathrm{mHz})\end{array}$} \\
\hline & 24-h & $\begin{array}{l}\text { wake } \\
\text { time }\end{array}$ & $\begin{array}{l}\text { sleep } \\
\text { time }\end{array}$ & 24-h & $\begin{array}{l}\text { wake } \\
\text { time }\end{array}$ & $\begin{array}{l}\text { sleep } \\
\text { time }\end{array}$ \\
\hline & & & $b$ & & & $\mathrm{~b}$ \\
\hline $\begin{array}{l}\text { Healthy } \\
\text { control subjects }\end{array}$ & $\left.\begin{array}{c}80 \\
(8)\end{array}\right]$ & $\left.\begin{array}{c}82 \\
(10)\end{array}\right]$ & $\left.\begin{array}{l}75 \\
(9)\end{array}\right]$ & $\begin{array}{l}262 \\
(11)\end{array}$ & $\begin{array}{l}267 \\
(12)\end{array}$ & $\left.\begin{array}{c}252 \\
(20)\end{array}\right]$ \\
\hline $\begin{array}{l}\text { Normo } \\
\text { albuminuria }\end{array}$ & $\begin{array}{l}76 \\
(9)\end{array}$ & {$\left[\begin{array}{c}80 \\
(11)\end{array}\right]$} & $\begin{array}{l}70 \\
(9)\end{array}$ & $\begin{array}{l}264 \\
(15)\end{array}$ & $\left.\begin{array}{c}266 \\
(13)\end{array}\right]$ & $\begin{array}{l}264 \\
(26)\end{array}$ \\
\hline $\begin{array}{l}\text { Micro } \\
\text { albuminuria }\end{array}$ & $\begin{array}{c}69 \\
(13)\end{array}$ & 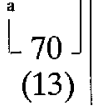 & $\begin{array}{c}\mathrm{b} \\
68 \\
(14)^{\mathrm{a}}\end{array}$ & $\begin{array}{c}271 \\
(15)\end{array}$ & $\begin{array}{r}275 \\
(17)\end{array}$ & $\begin{array}{l}270 \\
(20)\end{array}$ \\
\hline $\begin{array}{l}\text { Macro } \\
\text { albuminuria }\end{array}$ & $\begin{array}{c}66- \\
(15)\end{array}$ & $\begin{array}{l}69 \\
(15)\end{array}$ & $\begin{array}{c}61 \\
(12)\end{array}$ & $\begin{array}{l}257- \\
(13)\end{array}$ & $\begin{array}{c}255 \\
(8)\end{array}$ & $\begin{array}{l}257 \\
(17)\end{array}$ \\
\hline
\end{tabular}

${ }^{\mathrm{a}} p<0.05 ;{ }^{\mathrm{b}}$ significantly different from wake time $(p<0.05$; paired test)

Values shown for healthy control subjects and IDDM patients grouped according to urinary albumin excretion. Values shown are mean (SD)

normoalbuminuric patients did not differ from healthy control subjects. Short-term RR interval variability including both the LF and HF component was attenuated in patients with microalbuminuria compared to control subjects, and was severely reduced in macroalbuminuric patients. The LF component was most affected during wake time. The mean centre frequency of this oscillation was significantly more low frequent in micro and macroalbuminuric patients. Figure $4 \mathrm{~A}$ and B show individual values for spectral amplitude of the LF and HF component, in the four groups. The coefficient of component variance for the HF oscillations (CCV-HF) was significantly reduced in patients with micro and macroalbuminuria. Individual values displayed in Figure 5 shows that the normoalbuminuric and healthy control group appear alike. Numbers of patients with values at or below the lowest value of the control group were 0 of $12(0 \%), 7$ of 14 $(50 \%)$ and 7 of $11(65 \%)$ for the normo, micro and macroalbuminuric groups, respectively. An increasing degree of albuminuria was associated with an increased decay in all components of short-term RR interval variability $(p<0.01)$. The reduced amplitude of the $\mathrm{LF}, \mathrm{HF}$ and $\mathrm{CCV}-\mathrm{HF}$ component in the micro and macroalbuminuric groups was also present after correcting for impact of differences in leisure-time physical activity and smoking.
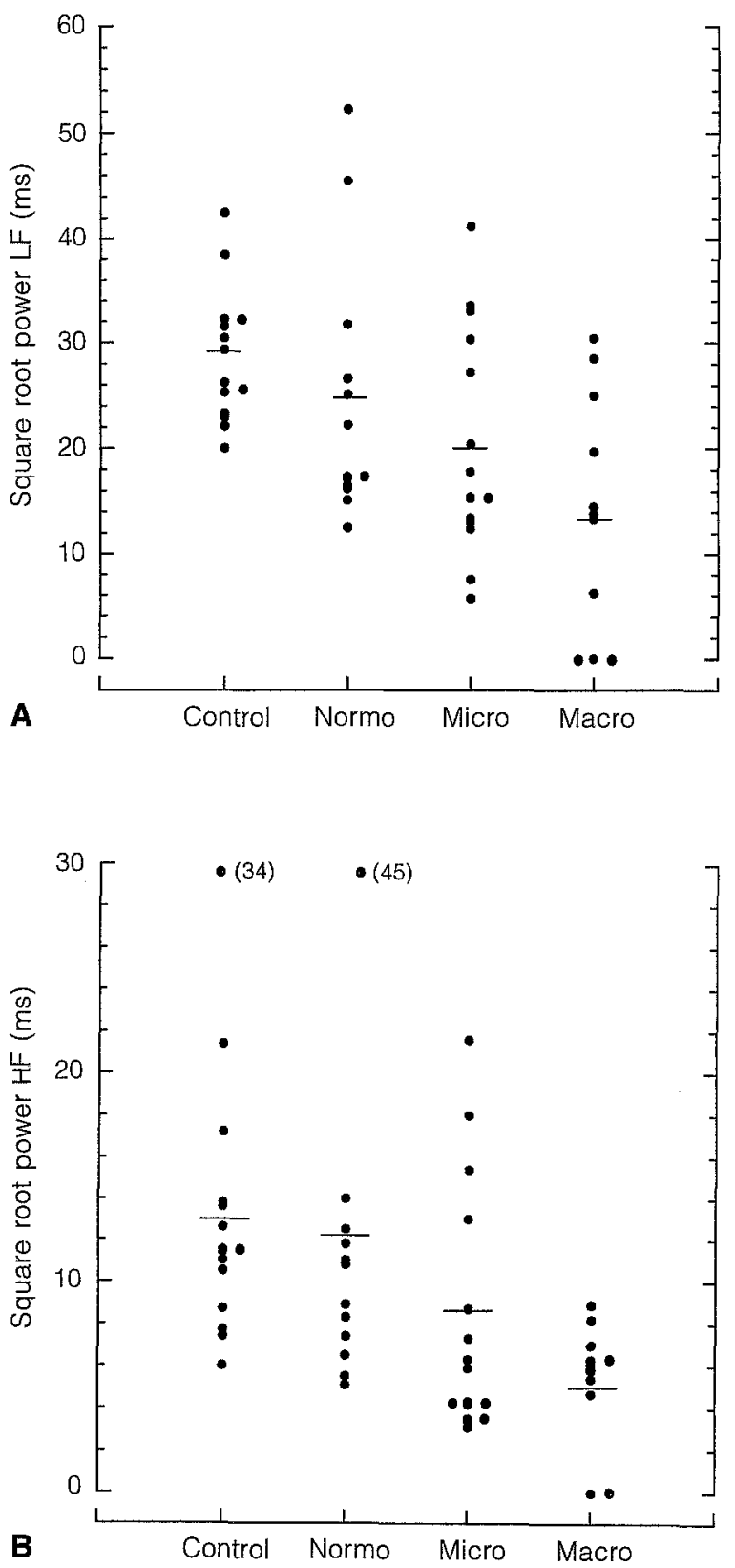

Fig.4. A: Mean 24-h spectral amplitude (square root of power) for the LF oscillation. B: Mean 24-h spectral amplitude for the HF oscillation. Individual values shown for healthy control subjects and IDDM patients according to urinary albumin excretion as normoalbuminuria (Normo), microalbuminuria (Micro) and macroalbuminuria (Macro). Horizontal bar shows mean value for group

\section{Discussion}

Determination of autonomic dysfunction in diabetic patients has so far primarily been based on a simple and standardized battery of bedside tests [30]. Evaluation of autonomic activity by $24-h$ RR interval variability, makes it possible to study the spontaneous activity in the autonomic system while the subject is ambulant $[15$, $16,20,26]$. Recent data indicate that diabetic patients may have another diurnal rhythm in autonomic bal- 


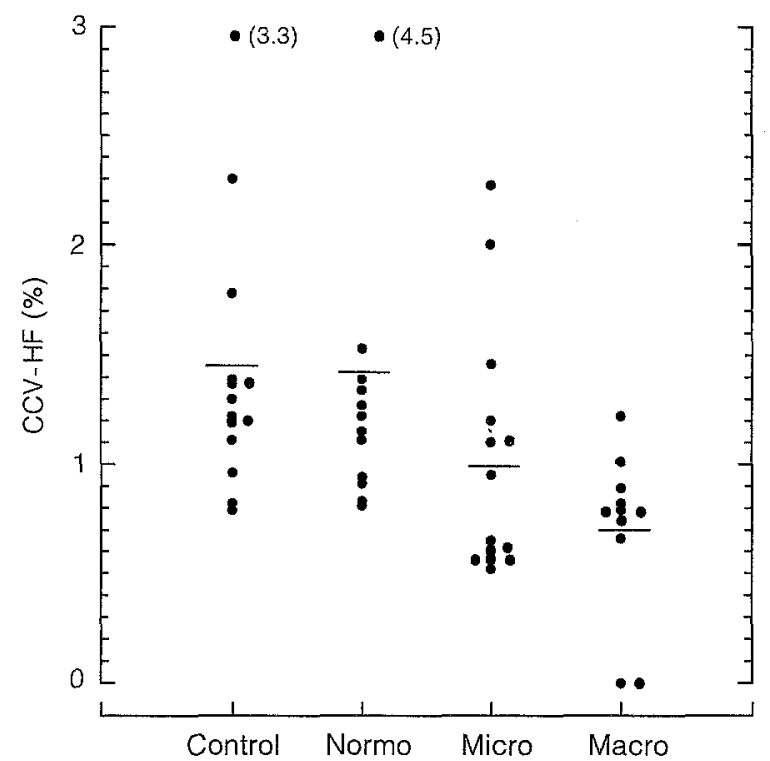

Fig. 5. Mean 24-h coefficient of component variance for the high frequency oscillation (square root of power/mean RR) (CCV$\mathrm{HF}$ ). Individual values shown for healthy control subjects and IDDM patients according to urinary albumin excretion as normoalbuminuria (Normo), microalbuminuria (Micro) and macroalbuminuria (Macro). Horizontal bar shows mean value for group

ance with a relative sympathetic overactivity during sleep [26]. The 24-h measurement seems to be more sensitive than bedside tests [15-17]. Clinical reports suggest that diabetic patients with severe autonomic neuropathy have a poor prognosis [10]. The issue has, however, not been addressed in large-scale prospective studies. Nevertheless, it is increasingly recognized that autonomic dysfunction contributes independently to the pathophysiology of sudden cardiac death $[6,7,31$, 32] in patients with ischaemic heart disease.

Diabetic patients have an increased risk of cardiovascular death which is not entirely explained by their different cardiovascular risk profile [33]. In IDDM patients the occurrence of macroalbuminuria (proteinuria) is associated with a high risk of early cardiovascular death $[1,34]$. The incidence of coronary heart disease is very high in the first years after the onset of macroalbuminuria [2]. The appearance of persistent slightly elevated urinary excretion of albumin - microalbuminuria, is a very good predictor of subsequent development of macroalbuminuria, as without intervention $85 \%$ develop proteinuria [3,4]. Microalbuminuria also predicts proteinuria and cardiovascular mortality in non-insulin-dependent diabetic patients $[21,35]$. This association between microangiopathy and macroangiopathy indicates that microalbuminuria is a marker of a generalized disease in the vascular wall of both small and large vessels.

Our study is the first which has addressed IDDM patients with a potential high risk for subsequent development of ischaemic heart disease. At the time of our in- vestigation they were without clinical signs of coronary heart disease. However, we did not perform invasive investigations, which leaves the possibility that some of the patients could have silent coronary heart disease. The severity and prevalence of cardiac autonomic dysfunction are, however, unlikely to be due to coronary disease. The small difference in diabetes duration between normo- and macroalbuminuric patients may explain some of the significant differences observed. Furthermore, we did find an identical control of blood glucose in the three groups. Our data, therefore, indicate that at the microalbuminuric stage a significant autonomic dysfunction is already present. However, the difference between the normo and microalbuminuric group was only present for CCV HF and centre frequency of LF.

The 24-h SD, which is a broad band measure of autonomic activity, was significantly reduced in microalbuminuric patients and severely reduced in macroalbuminuric patients. The $24-\mathrm{h} \mathrm{SD}$ is a strong independent predictor of sudden cardiac death in patients with coronary heart disease $[6,18,36,37]$. A 24-h SD less than $50 \mathrm{~ms}$ or a corresponding heart rate variability index less than 20 [6] indicates a profoundly increased risk of arrhythmic death in survivors of myocardial infarction $[6,18]$. These studies included diabetic patients but did not address their prognosis separately. One of our patients with microalbuminuria and three of the patients with macroalbuminuria had such severely reduced overall variability. An important component of overall variability is the basic diurnal rhythm in mean $R R$ - the wake sleep difference in mean RR. The physiological background for this basic circadian rhythm is unknown. But the increase in mean RR during the night is thought to be due to a withdrawal of sympathetic activity during sleep. The diminished day-night difference in mean RR in the micro and macroalbuminuric patients may therefore indicate an increased sympathetic activity during the night, as proposed previously [26]. The short-term components of $R R$ variability contribute less numerically to total variability, but their physiological origin is much more clear [19]. We have previously shown, by use of simple time-domain indices of vagal tone, that vagal activity is substantially reduced in micro and macroalbuminuric patients [16]. The present data, based on the spectral analysis of RR interval variability confirms this finding as the spectral amplitude of the HF component was significantly attenuated in both groups. For mathematical reasons, some of the reduction in intensity of the HF component in the micro and macroalbuminuric group may be due to the observed averaged shortening of mean RR (faster mean heart rate). However, the coefficient of component variance of the HF oscillation, which accounts for such differences in mean RR level, was still significantly reduced in both groups. Even more, a difference in vagal tone between normoalbuminuric and microalbuminuric patients became evident. Vagal activity was significantly 
higher during sleep in all three groups, as in the control group and as has been seen in other non-diabetic populations $[20,22]$. There was, however, a tendency towards a more pronounced reduction in vagal activity during sleep relative to time awake in micro and macroalbuminuric patients.

Sympathetic activity is mediated through RR interval oscillations in the frequency band of 0.0 to $0.15 \mathrm{~Hz}$. The spectral amplitude of the LF oscillations (0.04$0.15 \mathrm{~Hz}$ ) is mediated interactively by vagal and sympathetic activity. In the upright position, as during time awake, the spectral power is largely dependent on sympathetic activity [19]. The LF component was mostly affected during time awake, not only in its amplitude but also in a significant shift in centre frequency. As vagal tone was also reduced it is not possible to establish whether these changes are caused by an absolute or relative sympathetic overactivity in the micro and macroalbuminuric patients. However, in all four groups there were no significant differences in the wake/sleep ratio of the LF component.

These findings show that in IDDM patients with micro and macroalbuminuria both short and longterm components of RR interval variability are profoundly affected. This is caused primarily by a reduced vagal tone and very likely also by a relative sympathetic overactivity. This pattern of autonomic dysfunction is identical to the characteristics of patients at high risk of sudden cardiac death and of survivors of sudden cardiac death [7, 37-40]. It is not known whether these changes in our diabetic patients have identical prognostic and pathophysiological significance as to what has been described in mainly nondiabetic patients with coronary heart disease $[6,7]$. However, it is well recognized that normal vagal reactivity is an important protective factor in the pathophysiology of malignant ventricular arrhythmias [5, 31], as it acts as a buffer against high sympathetic activity [32]. The secondary preventive effects of betablockers on mortality and sudden cardiac death are particularly impressive in diabetic patients [41]. If diabetic patients generally lack vagal tone, they will be more sensitive to sympathetic overactivity. Recent data show that beta blockers may also improve vagal tone [42]. The effects of beta blockers on autonomic balance have, however, not been specifically addressed in diabetic patients with evidence of autonomic imbalance. Nevertheless, this indirect evidence supports the hypothesis that the autonomic dysfunction in diabetic patients may be of clinical importance, a point which should be clarified in prospective studies.

In conclusion the appearance of microalbuminuria in IDDM patients predicts subsequent development of macroalbumiuria and coronary heart disease. Our data indicate that these patients have impaired autonomic balance even at the microalbuminuric stage. The autonomic dysfunction in particular affects vagal tone but may also be associated with sympathetic overactivity.
This autonomic imbalance is very similar to what has been observed in patients with ischaemic heart disease at high risk for sudden cardiac death. The autonomic dysfunction may therefore have clinical importance for the subsequent risk of arrhythmic death, in these IDDM patients at potentially increased risk for coronary heart disease.

Acknowledgements. This study was supported by the Danish Heart Foundation, the Danish Medical Research Council, Nordisk Insulin Fond and Murermester Laurits Peter Christensens Foundation. We are greateful for the skilled technical assistance of Jette Absalonsen, Inger Buschmann, Birgit Dupont, Gertrud Naess-Schmit, and Merete Møller.

\section{References}

1. Borch-Johnsen K, Kreiner S (1987) Proteinuria: value as predictor of cardiovascular mortality in insulin dependent diabetes mellitus. BMJ 294: 1651-1654

2. Jensen T, Borch-Johnsen K, Kofoed-Enevoldsen A, Deckert $\mathrm{T}$ (1987) Coronary heart disease in young type 1 (insulin-dependent) diabetic patients with and without diabetic nephropathy: incidence and risk factors. Diabetologia 30: 144-148

3. Viberti GC, Hill RD, Jarrett RJ, Argyropoulos A, Mahmud U, Keen H (1982) Microalbuminuria as a predictor of clinical nephropathy in insulin-dependent diabetes mellitus. Lancet I: $1430-1432$

4. Mogensen CE, Christensen CK (1984) Predicting diabetic nephropathy in insulin-dependent patients. N Engl J Med 311: 89-93

5. Billman G, Schwartz PJ, Stone HL (1982) Baroreceptor reflex control of heart rate: a predictor of sudden cardiac death. Circulation 66: 874-880

6. Farrell TG, Bashir Y, Cripps Tet al. (1991) Risk stratification for arrhythmic events in postinfarction patients based on heart rate variability, ambulatory electrocardiographic variables and the signal averaged electrocardiogram. JACC 18: 687-697

7. Bigger JT, Fleiss JL, Steinman RC, Rolnitzky LM, Kleiger RE, Rottman JN (1992) Frequency domain measures of heart period variability and mortality after myocardial infarction. Circulation 85: 164-171

8. Bigger JT, Fleiss JL, Rolnitzky LM, Steinman RC (1993) Frequency domain measures of heart period variability to assess risk late after myocardial infarction. JACC 21: 729-736

9. Page MMcB, Watkins PJ (1978) Cardiorespiratory arrest and diabetic autonomic neuropathy. Lancet I: $14-16$

10. Ewing DJ, Campbell IW, Clarke BF (1976) Mortality in diabetic autonomic neuropathy. Lancet I: 601-603

11. Pont A, Rushing JL, Kelsey T, Jacobs L (1978) Cardiorespiratory arrest in diabetic neuropathy. Lancet I: 386-387

12. Garcia-Bunuel L (1978) Cardiorespiratory arrest in diabetic neuropathy. Lancet I: 935-936

13. Srinivasan G, Sanders G (1978) Cardiorespiratory arrest in diabetes. Lancet I: 504-505

14. Kahn JK, Sisson JC, Vinik AI (1988) Prediction of sudden cardiac death in diabetic autonomic neuropathy. $J$ Nucl Med 29: 1605-1606

15. Ewing DJ, Neilson JM, Shapiro CM, Stewart JA, Reid W (1991) Twenty four hour heart rate variability: effects of posture, sleep, and time of day in healthy controls and comparison with bedside tests of autonomic function in diabetic patients. Br Heart J 65: 239-244 
16. Mølgaard H, Christensen PD, Sørensen KE, Christensen CK, Mogensen CE (1992) Association of 24-hour cardiac parasympathetic activity and degree of nephropathy in insulin-dependent diabetic patients. Diabetes 41: 812-817

17. Malpas SC, Maling TJ (1990) Heart-rate variability and cardiac autonomic function in diabetes. Diabetes 39: 1177-1181

18. Kleiger RE, Miller JP, Bigger JT, Moss AJ (1987) Decreased heart rate variability and its association with increased mortality after acute myocardial infarction. Am J Cardiol 59: 256-262

19. Pomeranz B, Macaulay RJB, Caudill MA et al. (1985) Assessment of autonomic function in humans by heart rate spectral analysis. Am J Physiol 248:H151-H153

20. Furlan R, Guzzetti S, Crivellaro W et al. (1990) Continous 24-hour assessment of the neural regulation of systemic arterial pressure and RR variabilities in ambulant subjects. Circulation 81: $537-547$

21. Mogensen CE (1984) Microalbuminuria predicts clinical proteinuria and early mortality in maturity-onset diabetes. N Engl J Med 310: 356-360

22. Mølgaard H, Sørensen KE, Bjerregaard P (1991) Circadian variation and influence of risk factors on heart rate variability in healthy subjects. Am J Cardiol 68: 777-784

23. Mølgaard H, Hermansen K, Bjerregaard P (1994) Spectral components of short term RR interval variability in healthy subjects and effects of risk factors. Eur Heart J

24. Mølgaard H (1991) Evaluation of the Reynolds Pathfinder II system for 24 -hour heart rate variability analysis. Eur Heart J 12: 1153-1162

25. Hayano J, Skakibara Y, Yamada A et al. (1991) Accuracy of assessment of cardiac vagal tone by heart rate variability in normal subjects. Am J Cardiol 67: 199-204

26. Bernardi L, Ricordi L, Lazzari P et al. (1992) Impaired circadian modulation of sympathovagal activity in diabetes. Circulation 86 : $1443-1452$

27. Albrecht P, Cohen RJ (1988) Estimation of heart rate power spectrum bands from real-world data: dealing with ectopic beats and noisy data. Comput Cardiol 15: 311-314

28. Berger RD, Akselrod S, Gordon D, Cohen RJ (1986) An efficient algorithm for spectral analysis of heart rate variability. IEEE Trans Biomed Eng 33: 900-904

29. Kay SM, Marple SL (1981) Spectrum analysis-a modern perspective. Proc IEEE 69: 1380-1419
30. Ewing DJ (1984) Cardiac autonomic neuropathy: In: RJ Jarrett (ed) Diabetes and heart disease. Elsevier Science Publishers B. V. pp 99-132

31. Billman GE, Schwartz PJ, Stone HL (1984) The effects of daily exercise on susceptibility to sudden cardiac death. Circulation 69: 1182-1189

32. Lown B, Verrier RL (1976) Neural activity and ventricular fibrillation. N Engl J Med 294: 1165

33. Kannel WB, McGee DL (1979) Diabetes and cardiovascular disease: the Framingham Study. JAMA 241: 2035-2038

34. Borch-Johnsen K, Andersen PK, Deckert T (1985) The effect of proteinuria on relative mortality in type 1 (insulin-dependent) diabetes mellitus. Diabetologia 38: 590-596

35. Jarrett RJ, Viberti GC, Argyropoulos A, Hill RD, Mahmud U, Murrells TJ (1984) Microalbuminuria predicts mortality in non-insulin-dependent diabetes. Diabet Med 1: 17-19

36. Rich MW, Saini JS, Kleiger RE, Carney RM, Velde A, Freedland KE (1988) Correlation of heart rate variability with clinical and angiographic variables and late mortality after coronary angiography. Am J Cardiol 62: 714-717

37. Singer DH, Martin GJ, Magid N et al. (1988) Low heart rate variability and sudden cardiac death. J Electrocardiol 21 [Suppl]:S46-S55

38. Bigger JT, Kleiger RE, Fleiss Л, Rolnitzky LM, Steinman RC, Miller JP (1988) Components of heart rate variability measured during healing of acute myocardial infarction. Am J Cardiol 61: 208-215

39. Huikuri HV, Linnaluoto MK, Seppanen T et al. (1992) Circadian rhythm of heart rate variability in survivors of cardiac arrest. Am J Cardiol 70: 610-615

40. Dougherty CM, Burr RL (1992) Comparison of heart rate variability in survivors and nonsurvivors of sudden cardiac arrest. Am J Cardiol 70: 441-448

41. Kjekshus J, Gilpin E, Cali G, Blackey AR, Henning H, Ross Jr J (1990) Diabetic patients and beta-blockers after myocardial infarction. Eur Heart J 11: 43-50

42. Mølgaard H, Mickley H, Pless P, Bjerregaard P, Møller M (1993) Effects of Metoprolol on heart rate variability in survivors of acute myocardial infarction. Am J Cardiol 71: 13571359 